\title{
African stock markets: multiple variance ratio tests of random walks ${ }^{1}$
}

\author{
GRAHAM SMITH*, KEITH JEFFERIS $\$$ and HYUN-JUNG RYOO§ \\ *§Department of Economics, School of Oriental \& African Studies, University of \\ London, Thornhaugh Street, Russell Square, London WC1HOXG and †Bank of \\ Botswana, Private Bag 154, Gaborone, Botswana \\ E-mail:*gs8@soas.ac.uk, †keithj@bob.bw and §hp6@soas.ac.uk
}

This paper identifies four categories of formal stock market in Africa: South Africa, medium-sized markets, small new markets which have experienced rapid growth, and small new markets which have yet to take off. The hypothesis that a stock market price index follows a random walk is tested for South Africa, five medium-sized markets (Egypt, Kenya, Morocco, Nigeria and Zimbabwe) and two small new markets (Botswana and Mauritius) using the multiple variance ratio test of Chow and Denning (Journal of Econometrics, 58, 385-401, 1993). The hypothesis is rejected in seven of the markets because of autocorrelation of returns. For the South African market, the stock price index follows a random walk. The paper also suggests factors which may contribute to whether or not an equity market follows a random walk.

\section{INTRODUCTION}

The increasing prominence of stock markets in developing countries - emerging markets - is one of the most striking features of international financial development over the past two decades. Although the most important emerging markets are in Latin America and Asia, recent years have seen a number of new stock markets in Africa - indeed, it seems that no programme of financial sector reform in Africa is complete unless it includes the establishment of a new stock market or the rehabilitation of an old one. The establishment of stock markets is generally seen as beneficial for a variety of reasons, including their ability to attract inward portfolio investment, boost domestic savings, and improve the pricing and availability of capital for domestic investment. More generally, stock markets are seen as enhancing the operations of the domestic financial system in general and the capital market in particular (Jefferis, 1995; Kenny and Moss, 1998).

However the ability of stock markets to play the role that is ascribed to them depends on their efficiency (in the financial sense). If they are to help improve the operation of the capital market, then the role of stock markets in the allocation and pricing of capital, and the pricing of risk, is crucial. Hence much analysis of stock markets around the world focuses on the price formation process (for stock prices) or, equivalently, the characteristics and determination of stock returns. A common test for market efficiency is to see whether a price follows a random walk - a test that can be applied at the level of individual stocks, groups of stocks, or a market index. If a stock price or market index does follow a random walk, then it can be concluded that investors will be unable consistently to earn abnormal returns. This is consistent with stocks being appropriately priced at their equilibrium values. If a market does not follow a random walk, then there may be distortions in the pricing of capital and risk, which has implications for the allocation of capital within an economy.

While the more-established emerging markets have been the topic of extensive analysis of market efficiency, the same cannot be said for African markets, largely because many of them are new and very small, and there has often

* Author to whom correspondence should be addressed.

${ }^{1}$ This paper represents the personal views of the authors and not necessarily those of their respective institutions. 
Table 1. African stock markets, 1997, ranked by turnover

\begin{tabular}{|c|c|c|c|c|}
\hline & $\begin{array}{l}\text { Capitalization } \\
\text { US\$ milion }\end{array}$ & $\begin{array}{l}\text { Turnover } \\
\text { US\$ million }\end{array}$ & $\begin{array}{l}\text { Turnover } \\
\text { ratio }(\%)\end{array}$ & No. of stocks \\
\hline Malawi & 108 & $\mathrm{n} / \mathrm{a}$ & $\mathrm{n} / \mathrm{a}$ & 2 \\
\hline Swaziland & 129 & $\mathrm{n} / \mathrm{a}$ & $\mathrm{n} / \mathrm{a}$ & 4 \\
\hline Zambia & 705 & 9 & 1.8 & 6 \\
\hline Cote D'Ivoire & 1276 & 24 & 2.3 & 35 \\
\hline Namibia & 689 & 24 & 4.0 & 13 \\
\hline Ghana & 1138 & 47 & 3.7 & 21 \\
\hline Botswana & 615 & 74 & 12.3 & 12 \\
\hline Kenya & 1824 & 104 & 5.7 & 58 \\
\hline Nigeria & 3646 & 132 & 3.9 & 182 \\
\hline Mauritius & 1665 & 137 & 8.2 & 40 \\
\hline Tunisia & 2321 & 285 & 8.3 & 34 \\
\hline Zimbabwe & 1969 & 532 & 17.1 & 64 \\
\hline Morocco & 12177 & 1048 & 10.2 & 49 \\
\hline Egypt & 20830 & 5859 & 33.5 & 650 \\
\hline South Africa & 232069 & 44893 & 18.3 & 642 \\
\hline Total & 281630 & 53169 & 18.9 & 1819 \\
\hline Excluding South Africa & 49561 & 8276 & 16.7 & 1177 \\
\hline
\end{tabular}

Source: IFC (1998); Flemings Research (1997)

been a problem obtaining data series of sufficient frequency and duration. The aim of this paper is to carry out a rigorous test of the random walk hypothesis on eight of the largest African stock exchanges, for which an adequate dataset has been compiled. On the basis of the results of these tests, the paper then suggests factors that may contribute to whether or not a market does follow a random walk - factors which will also indicate whether a stock market can play a positive role in the operation of capital markets.

The rest of this paper is organized as follows. The next section describes the equity markets and their characteristics. Section III discusses variance ratio tests of the random walk hypothesis. In Section IV the data set is described and Section V discusses the results obtained. Section VI provides a brief conclusion.

\section{THE EQUITY MARKETS}

At the end of 1997 there were 15 formal stock markets in Africa (see Table 1). These can usefully be divided into four categories:

1. South Africa, which dominates other African stock markets in terms of both size and sophistication.

2. A group of medium-sized markets, many of which have been established for a long time (e.g., Egypt, Nigeria, Zimbabwe).

3. Small new markets that have shown rapid growth (e.g., Botswana, Mauritius, Ghana).

4. Small new markets that have yet to take off (e.g., Swaziland, Zambia, Malawi).
With the exception of South Africa, African stock markets are extremely small by world standards. Together, the 15 markets apart from South Africa accounted for only $0.2 \%$ of world stock market capitalization at the end of 1997 , and $2.2 \%$ of emerging market capitalization. In contrast, South Africa - which accounts for $82 \%$ of African stock market capitalization - is quite large by world standards. With a capitalization of US\$232 billion at the end of 1997 , South Africa was then the third largest emerging market (after Taiwan and Brazil), and the 16th largest equity market in the world. All African markets (including South Africa) tend to lack liquidity, however, and when ranked by turnover rather than market capitalization their relative position is diminished.

The markets covered in this study (see Table 2) represent eight of the nine largest stock markets in Africa (measured by turnover) and comprise all of the markets for which data of adequate time span and frequency are available for our purposes. Five of them are included in the IFC's Global Emerging Market Index (IFCG) although, apart from South Africa, they have very small weights in the IFCG index. The markets are drawn from three of the four groups noted above: South Africa; five established medium sized markets (Egypt, Nigeria, Morocco, Zimbabwe, and Kenya), and two small new markets (Mauritius and Botswana). Although most African stock markets are relatively small, many have grown rapidly in recent years, and there have been very rapid increases in capitalization and turnover over the past decade. Turnover, for instance, increased at an average annual rate of 46\% (measured in US\$ terms) between 1988 and 1997 , compared to only $15 \%$ a year for emerging markets 
Table 2. Markets included in the study

\begin{tabular}{|c|c|c|c|c|c|}
\hline & \multirow{2}{*}{$\begin{array}{l}\text { Date } \\
\text { established }\end{array}$} & \multirow{2}{*}{$\begin{array}{l}\text { Turnover (US\$): } \\
\text { avg. annual growth } \\
\text { rate, 1988-1997 [1] }\end{array}$} & \multirow{2}{*}{$\begin{array}{l}\text { Share of } \\
\text { IFGG Index } \\
1997\end{array}$} & \multicolumn{2}{|c|}{ Correlation [3] } \\
\hline & & & & S\&P 500 & FT All Share \\
\hline Egypt & 1883 & $60 \%$ & $0.83 \%$ & -0.01 & 0.00 \\
\hline South Africa & 1887 & $24 \%$ & $9.19 \%$ & 0.24 & 0.26 \\
\hline Zimbabwe & 1896 & $32 \%$ & $0.11 \%$ & 0.07 & 0.06 \\
\hline Morocco & 1929 & $65 \%$ & $0.77 \%$ & 0.01 & 0.02 \\
\hline Kenya & 1954 & $46 \%$ & - & 0.01 & 0.02 \\
\hline Nigeria & 1960 & $38 \%$ & $0.26 \%$ & 0.01 & 0.05 \\
\hline Botswana & 1989 & $36 \%$ & - & 0.01 & 0.04 \\
\hline Mauritius & 1989 & $65 \%$ & - & -0.04 & 0.03 \\
\hline Average (unweighted mean) & & $46 \%$ & & & \\
\hline Average excl. SA (weighted mean) & {$[2]$} & $58 \%$ & & & \\
\hline Average incl. SA (weighted mean) & [2] & $29 \%$ & & & \\
\hline All emerging markets & & $15 \%$ & & & \\
\hline
\end{tabular}

Notes:

[1] Growth rates calculated using OLS

[2] Weights are end-1997 capitalizations

[3] Correlation of returns

Sources: IFC (1998); Morgan Stanley (1993); Primark Datastream

as a whole. At the same time, many of these markets have performed well in terms of returns for investors. Although in many cases also they have been characterized by high levels of volatility, these markets tend to exhibit relatively low correlations with other stock markets internationally.

A number of factors have contributed to the expansion and growth of African stock markets. Many countries have been undergoing economic reform programmes that have involved a reduction in the role of the state in the economy and a strengthening of the role of the private sector. This has been accompanied by a greater role for market forces in price determination and the allocation of both real and financial resources. Financial sector reforms have often included the establishment of new stock markets, or improving the environment in which existing stock markets operate. Furthermore, privatization programmes in several countries have involved the listing of shares in formerly nationalized firms, which are often very large in relation to the size of national economies, thus providing a supply of new shares and a further boost to stock market development.

This process has been accompanied by increased attention from international investors. Their interest reflects the growing size of African markets, along with the potential for high returns accompanied by the diversification benefits resulting from low correlations with other markets. At the same time many of the barriers to entry that have previously restricted the participation of foreign investors in many African markets are being progressively eased. One 1993 report noted the following problems facing foreign investors:
Most African countries with a stock market lack a freely convertible currency, and the margin between official and market exchange rates can be as high as 30\%. Except for South African firms, one brokerage house in Zimbabwe, and a new research concern in Ghana, none of Africa's investment houses writes research reports. Similarly, there appears to be a four- to fivemonth lag on earnings reporting, and timely news on listed companies is hard to come by. Many companies do not publish their income statements or balance sheets on a regular basis, as the generally inactive stock markets don't seem to require them. Finally, very few banks meet the minimal capitalization requirements for custodial banks outlined by the SEC, so there is much delay in seeking suitable custody and settlement arrangements (Morgan Stanley, 1993:14).

Since that time there have been some improvements: many countries have liberalized exchange controls on both current and capital account, making entry and exit easier, and direct restrictions on foreign ownership of shares have also been relaxed, although most of the markets considered here do still retain some such controls.

The lack of liquidity remains a serious problem for African markets, however. Even the most liquid of the markets considered here - Egypt, with a turnover ratio of $33 \%$ - fares poorly by world standards. The ten most liquid markets in the world in 1997 all had turnover ratios in excess of $100 \%$, and all of the African markets had liquidity below the global median (35\%). Lack of liquidity can stem from both sides of the market. On the supply side, many shares in listed companies are held by controlling 
interests - often foreign parent companies - leaving relatively small proportions of shares available for public trading. This can have implications on the demand side, especially in small markets, where local and foreign institutional investors know that 'the costs of trading in and out of African equities are high and that positions once sold may not be easily re-established' (Flemings Research, 1997, p. 2).

The eight markets included in this study are now considered.

\section{South Africa}

The Johannesburg Stock Exchange was established in the 19th century in order to raise finance for emerging gold mining ventures. Although very large in terms of capitalization, liquidity remains low due to the domination of share ownership by large conglomerates linked either to mining companies or financial holding companies. This concentration of ownership is partly a result of strict exchange controls on the capital account, which restricted South African firms from exporting capital and left them with little choice but to take over other domestic firms. The JSE has benefited from substantial inflows of foreign portfolio investment since the ending of apartheid and the lifting of sanctions in 1994. There are no restrictions on the ownership of shares by foreigners, although prior to March 1995 transactions had to be carried out using the 'financial rand', a dual exchange rate which applied to capital transactions. Since the abolition of the dual exchange rate regime, foreign investors have not been subject to any exchange control regulations, although domestic investors remain restricted in their ability to export capital. The domination of the JSE by the conglomerates has declined since 1994, as a result of inflows of foreign capital and various affirmative action/black empowerment deals. The JSE moved to a screen based electronic trading system in 1996. It operates as part of a relatively sophisticated financial sector, characterized by a wide range of financial institutions, markets, and information flows, which in many respects is more representative of a developed than a developing country. However, there have been some concerns about insider trading given the prevalence of suspicious share price movements prior to major announcements.

\section{Egypt}

The Egyptian stock exchange is the second largest in this study by both capitalization and turnover, and is also the oldest in Africa, predating the JSE by four years. For much of its existence however its role has been stifled by excessive bureaucracy and regulation, and a large proportion of the listed shares have been illiquid. Nevertheless, recent moves towards deregulation and privatization have given the mar- ket a boost. However, the potential efficiency of the market is constrained by a daily $5 \%$ stock price fluctuation limit.

\section{Morocco}

Like Egypt, Morocco has a relatively old stock exchange (the Casablanca Stock Exchange) that has been inactive for long periods. Again, deregulation and privatization have boosted the market in recent years. Although there are no restrictions on foreign ownership, foreign participation in the market is low. This is partly a result of exchange control restrictions on domestic investors who have few domestic or foreign investment alternatives to the stock exchange. Like Egypt, Morocco has been included in the IFC Investible (IFCI) Index in February 1997, and this is likely to boost foreign participation in the market.

\section{Zimbabwe}

Another long-established market, characterized as 'a dozy club with two members' (Cazenove, 1997, p. 44) prior to the advent of Zimbabwe's IMF-inspired Economic Structural Adjustment Programme (ESAP) in 1991. The most important boost to the market came with the opening of the exchange to foreign investors in May 1993, along with a major relaxation of exchange controls. Nevertheless, foreign ownership is still restricted, with individual foreign investors limited to $10 \%$ of a company's shares, and foreign investors collectively to $40 \%$. Continued economic and political problems, and inconsistent implementation of structural adjustment and economic reform policies have, however, made the market highly volatile, especially for foreign investors. For instance, the (US dollar-based) IFC total return index recorded a gain of $143 \%$ in 1993 , $66 \%$ in 1996 , and a fall of $53 \%$ in 1997.

\section{Nigeria}

The Nigerian Stock Exchange has been primarily a forum for trading government bonds rather than equities throughout most of its existence, but has shown some signs of life since 1996. Equity trading has been constrained by restrictions on foreign ownership, and long-standing political and economic problems, and liquidity has been extremely low. However, despite the inconsistent implementation of economic reform programmes, privatization has been quite widespread and this has helped the stock market. Nevertheless the market is effectively closed to foreign investors and is driven by domestic sentiment.

\section{Kenya}

The Kenyan market has had a very similar history to that of Zimbabwe, with an upsurge in activity since 1993 due to economic reform, privatization, relaxation of restrictions 
on foreign investors and of exchange controls. At the same time the reform programme has been inconsistent and political problems remain, leading to market volatility, especially in dollar terms.

\section{Mauritius}

The Stock Exchange of Mauritius (SEM) has developed rapidly in a short period of time, from its establishment with five companies in 1989 to 40 listed companies by 1997. The listed companies cover a wide range of economic activities, including manufacturing, tourism, sugar and finance. Although the market remains small and not all that liquid, it is helped by the absence of restrictions on foreign ownership, and foreign investors play an active role in the market.

\section{Botswana}

The Botswana Stock exchange is the smallest market (by both capitalization and turnover) of those considered here. Established in 1989 with five listed companies, it had only grown to 12 listed companies by 1997. The listed companies are concentrated in finance and services, with little representation from manufacturing and none from the mining sector on which the economy depends. Foreign portfolio investors are limited to $10 \%$ individually and $55 \%$ collectively of company stocks, and play an important role in the market. Despite the small number of stocks and only one broker (two since early 1998), the market is more liquid than some larger African markets.

\section{METHODOLOGY: MULTIPLE VARIANCE RATIO TESTS}

Consider the following random walk with drift process

$$
p_{t}=p_{t-1}+\mu+\varepsilon_{t}
$$

or

$$
\Delta p_{t}=\mu+\varepsilon_{t}
$$

in which $p_{t}$ is the natural logarithm of a stock price index, $\mu$ is an arbitrary drift parameter and $\varepsilon_{t}$ is a random disturbance term. The $\varepsilon_{t}$ satisfy $\mathrm{E}\left[\varepsilon_{t}\right]=0$, and $\mathrm{E}\left[\varepsilon_{t} \varepsilon_{t-g}\right]=0, g \neq 0$, for all $t$. The random walk hypothesis has two implications: uncorrelated residuals and a unit root. Variance ratio tests focus on uncorrelated residuals and are preferable to unit root tests for two reasons: the latter focus on establishing whether a series is difference stationary or trend stationary (Campbell et al., 1997) and are known to have very low power and cannot detect some departures from the random walk, Shiller and Perron (1985), Hakkio (1986) and Gonzalo and Lee (1996). This contrasts with the multiple variance ratio test which has good size and power properties, Chow and Denning (1993).

With uncorrelated residuals and hence uncorrelated increments in $p_{t}$, the variance of these increments increases linearly in the observation interval,

$$
\operatorname{Var}\left(p_{t}-p_{t-q}\right)=q \operatorname{Var}\left(p_{t}-p_{t-1}\right)
$$

in which $q$ is any positive integer. The variance ratio is given by

$$
\operatorname{VR}(q)=\frac{\frac{1}{q} \operatorname{Var}\left(p_{t}-p_{t-q}\right)}{\operatorname{Var}\left(p_{t}-p_{t-1}\right)}=\frac{\sigma^{2}(q)}{\sigma^{2}(1)}
$$

and under the null hypothesis $\operatorname{VR}(q)=1$.

Lo and MacKinlay (1988) generate the asymptotic distribution of the estimated variance ratios and derive two test statistics, $Z(q)$ and $Z^{*}(q)$, under the null hypotheses of homoscedastic increments random walk and heteroscedastic increments random walk respectively. The appendix provides the formulae. If the null is true then the associated test statistic has an asymptotic standard normal distribution. Their test statistics are both flexible and simple to compute. However, the Lo and MacKinlay approach focuses on testing individual variance ratios for a specific aggregation interval, $q$, but the random walk hypothesis requires that $\operatorname{VR}(q)=1$ for all $q$. The multiple variance ratio (MVR) test provides a joint test through controlling the size of the test.

Chow and Denning (1993) provide a procedure for the multiple comparison of the set of variance ratio estimates with unity. For a single variance ratio test, under the null hypothesis, $\operatorname{VR}(q)=1$ and hence $\mathrm{M}_{\mathrm{r}}(q)=\operatorname{VR}(q)-1=0$. Now consider a set of $m$ variance ratio tests $\left\{\mathrm{M}_{\mathrm{r}}\left(q_{i}\right) \mid i=\right.$ $1,2, \ldots, m\}$ associated with the set of aggregation intervals $\left\{q_{i} \mid i=1,2, \ldots, m\right\}$. Under the random walk null hypothesis there are multiple sub-hypotheses

$$
\begin{array}{ll}
H_{0 i}: \mathbf{M}_{\mathrm{r}}\left(q_{i}\right)=0 & \text { for } i=1,2, \ldots, m \\
H_{1 i}: \mathbf{M}_{\mathrm{r}}\left(q_{i}\right) \neq 0 & \text { for any } i=1,2, \ldots, m
\end{array}
$$

Rejection of any one or more $H_{0 i}$ rejects the random walk null hypothesis. Consider a set of Lo and MacKinlay test statistics, say $\mathrm{Z}(q),\left\{\mathrm{Z}\left(q_{i}\right) \mid i=1,2, \ldots, m\right\}$. Since the random walk null hypothesis is rejected if any of the estimated variance ratios is significantly different from one, it is only necessary to focus on the maximum absolute value in the set of test statistics. The core of Chow and Denning's MVR test is based on the result

$$
\mathrm{PR}\left[\max \left(\left|\mathrm{Z}\left(q_{1}\right)\right|, \ldots,\left|\mathrm{Z}\left(q_{m}\right)\right|\right) \leqslant \operatorname{SMM}(\alpha ; m ; T)\right] \geqslant 1-\alpha
$$

in which $\operatorname{SMM}(\alpha ; m ; T)$ is the upper $\alpha$ point of the Studentized Maximum Modulus (SMM) distribution with 
Table 3. Summary statistics for weekly returns, $\Delta p_{t}$

\begin{tabular}{lcccccccr}
\hline & Botswana & Egypt & \multicolumn{1}{c}{ Kenya } & Mauritius & Morocco & Nigeria & South Africa & Zimbabwe \\
\hline Mean & 0.0041 & 0.0046 & 0.0028 & 0.0032 & 0.0047 & 0.0065 & 0.0011 & 0.0042 \\
Median & 0.0024 & 0.0007 & 0.0006 & 0.0013 & 0.0000 & 0.0055 & 0.0025 & 0.0043 \\
Standard deviation & 0.0108 & 0.0261 & 0.0273 & 0.0175 & 0.0127 & 0.0156 & 0.0244 & 0.0304 \\
Skewness & 2.26 & 1.13 & 4.31 & 0.39 & 1.14 & 0.74 & -1.12 & -0.40 \\
Kurtosis & 17.01 & 5.80 & 39.46 & 5.85 & 8.61 & 4.26 & 8.28 & 5.99 \\
Jarque-Bera & 4055.84 & 158.64 & 26273.14 & 164.07 & 688.36 & 38.72 & 616.31 & 179.94 \\
\hline
\end{tabular}

Note: The 0.05 critical value for the Jarque-Bera test is 5.99

parameters $m$ and $T$ (sample size) degrees of freedom. Asymptotically, when $T$ is infinite,

$$
\operatorname{SMM}(\alpha ; m ; \infty)=Z_{\alpha^{*} / 2}
$$

in which $\alpha^{*}=1-(1-\alpha)^{1 / m}$. Chow and Denning control the size of a MVR test by comparing the calculated values of the standardized test statistics, either $\mathrm{Z}\left(q_{i}\right)$ or $\mathrm{Z}^{*}\left(q_{i}\right)$, with the SMM critical values. ${ }^{2}$ If the maximum absolute value of, say, $\mathrm{Z}\left(q_{i}\right)$ is greater than the SMM critical value at a predetermined significance level then the random walk hypothesis is rejected.

Chow and Denning (1993) using a Monte Carlo experiment, examine the size and power of their MVR test. Under both a homoscedastic i.i.d. null and a heteroscedastic i.i.d. null and using the asymptotic SMM critical values, the empirical test size is close to the nominal test size. Furthermore, it is much closer to the nominal test size than arises from testing individual variance ratios separately using the standard normal distribution. If the size of the joint test is not controlled, at the $5 \%$ significance level, empirical size is three times nominal size for small samples of 64 observations rising to 4 times nominal size for large samples. The MVR test has comparable power to unit root tests against an $\mathrm{AR}(1)$ alternative and is much more powerful against $\operatorname{ARIMA}(1,1,1)$ and $\operatorname{ARIMA}(1,1,0)$ alternatives. The latter is especially interesting: an $\operatorname{ARIMA}(1,1,0)$ process of $p_{t}$ is equivalent to an $\operatorname{AR}(1)$ process of $\Delta p_{t}$ with positive autocorrelation parameter. Lo and MacKinlay (1988) report $\widehat{\mathrm{VR}}(1)$ for $q=2$ in the range 1.05 to 1.30 implying an autocorrelation parameter in the range from 0.05 to 0.30 . The $\operatorname{ARIMA}(1,1,0)$ process could be the more relevant alternative.

\section{THE DATA AND THEIR PROPERTIES}

The data used are weekly commencing in the third week of January 1990 and ending in the last week of August 1998 (450 observations) except for Egypt and Nigeria which series start in the first week of January 1993 (295 observations) and 1994 (243 observations) respectively. Where series are available at a higher frequency than weekly, the data refer to Wednesdays to minimize day-of-the-week effects. In general, broadly-based indices are used which are representative of the market as a whole. The source of the Botswana index is Dataworld all other series are from Primark Datastream. The Botswana Share Market Index, the EFG Price Index for Egypt, the Nairobi Stock Exchange Index, the Stock Exchange of Mauritius Index (SEMDEX), the Casablanca CFG 25, for Nigeria the IFC Global Index and the Johannesburg Stock Exchange JSEActuaries All Share Index are used. The Zimbabwe Stock Exchange does not produce an all-share index only separate ones for the industrial and mining sectors. We use the former since the industrial sector dominates the market. ${ }^{3}$ All indices are in local currency and have value weights.

Table 3 reports descriptive statistics of weekly returns. Average stock returns are positive for all markets. The statistics confirm that weekly returns in African markets are similar to those in many other markets in that they are not normally distributed. Weekly returns are leptokurtic, that is, more sharply peaked about the mean than the normal distribution. Returns on the stock exchanges of South Africa and Zimbabwe are negatively skewed; for all other markets they are skewed to the right.

\footnotetext{
2 Tables of percentage points of the SMM which are appropriate for carrying out MVR tests at the 0.05 level are provided in Hahn and Hendrickson (1971, p. 325) and Miller (1981, pp. 239 and 278). Miller's Table III p. 239 is useful for samples $\leqslant 120$ and $\infty$. Critical values for large samples can also be generated from the standard normal distribution using Equation 7.

${ }^{3}$ The Harare brokers Fleming Martin produce an in-house all-share index but only from 1995. They report there is little difference between their index and the ZSE Industrial Index so we choose to use the latter because with the larger sample size our tests of the random walk hypothesis have greater power.
} 
Table 4. Multiple variance ratio tests

\begin{tabular}{|c|c|c|c|c|c|}
\hline & & $q=2$ & $q=4$ & $q=8$ & $q=16$ \\
\hline \multirow[t]{3}{*}{ Botswana } & $\overline{\operatorname{VR}}(q)$ & 1.39 & 2.27 & 3.63 & 5.34 \\
\hline & $Z(q)$ & 8.21 & 14.37 & 18.80 & $20.87^{*}$ \\
\hline & $Z^{*}(q)$ & $23.73^{*}$ & 20.60 & 14.64 & 11.61 \\
\hline \multirow[t]{3}{*}{ Egypt } & $\widehat{\operatorname{VR}}(q)$ & 1.37 & 1.89 & 2.33 & 3.15 \\
\hline & $Z(q)$ & 6.27 & 8.18 & 7.71 & $8.38 *$ \\
\hline & $Z^{*}(q)$ & $9.97 *$ & 9.10 & 5.60 & 3.95 \\
\hline \multirow[t]{3}{*}{ Kenya } & $\widehat{\operatorname{VR}}(q)$ & 1.46 & 2.02 & 2.51 & 2.54 \\
\hline & $Z(q)$ & 9.84 & $11.59^{*}$ & 10.78 & 7.45 \\
\hline & $Z^{*}(q)$ & $39.52 *$ & 16.31 & 11.37 & 2.97 \\
\hline \multirow[t]{3}{*}{ Mauritius } & $\overline{\mathbf{V R}}(q)$ & 1.29 & 1.60 & 1.98 & 2.44 \\
\hline & $Z(q)$ & 6.12 & 6.80 & $7.00 *$ & 6.93 \\
\hline & $Z^{*}(q)$ & $7.67 *$ & 7.09 & 4.97 & 3.61 \\
\hline \multirow[t]{3}{*}{ Morocco } & $\widehat{\mathrm{VR}}(q)$ & 1.01 & 1.18 & 1.60 & 1.93 \\
\hline & $Z(q)$ & 0.31 & 2.06 & 4.28 & $4.46^{*}$ \\
\hline & $Z^{*}(q)$ & 0.37 & 1.67 & $3.39 *$ & 1.69 \\
\hline \multirow[t]{3}{*}{ Nigeria } & $\widehat{\mathrm{VR}}(q)$ & 1.56 & 2.91 & 5.40 & 9.39 \\
\hline & $Z(q)$ & 8.71 & 15.87 & 23.11 & $29.67 *$ \\
\hline & $Z^{*}(q)$ & 13.94 & $20.51 *$ & 20.09 & 12.98 \\
\hline \multirow[t]{3}{*}{ South Africa } & $\widehat{\mathbf{V R}}(q)$ & 0.96 & 1.05 & 1.10 & 1.19 \\
\hline & $Z(q)$ & -0.86 & 0.56 & 0.75 & 0.90 \\
\hline & $Z^{*}(q)$ & -0.96 & 0.52 & 0.58 & 0.40 \\
\hline \multirow[t]{3}{*}{ Zimbabwe } & $\overline{\mathbf{V R}}(q)$ & 1.47 & 2.11 & 2.80 & 3.96 \\
\hline & $Z(q)$ & 10.02 & 12.57 & 12.90 & $14.24^{*}$ \\
\hline & $Z^{*}(q)$ & 14.85 & $17.87^{*}$ & 11.27 & 8.61 \\
\hline
\end{tabular}

Note: The 0.05 critical value for $Z(q)$ and $Z^{*}(q)$ is 2.49

\section{RESULTS}

Table 4 reports the results of variance ratio tests on the logarithms of the eight stock price indices for sampling intervals of $2,4,8$ and 16 weeks. For each interval, the estimate of the variance ratio, $\widehat{\mathrm{VR}}(q)$, is reported and the test statistics for the null hypotheses of homoscedastic, $Z(q)$, and heteroscedastic, $Z^{*}(q)$, increments random walks. Using the multiple variance ratio procedure, the maximum absolute values of the test statistics are focused on. With the present sample sizes and $m=4$, the 0.05 critical value is 2.49 . For each set of tests the maximum absolute value of the test statistic is identified with an asterisk when it exceeds this critical value.

First consider the results for the Botswana stock market. The null hypothesis that the logarithm of the stock price index follows a homoscedastic random walk is rejected since $Z(16)=20.87>2.49$. This rejection of the hypothesis under homoscedasticity could result from heteroscedasticity and/or autocorrelation in the stock price series. However, $Z^{*}(2)=23.73>2.49$ rejecting the null of a heteroscedastic random walk. Therefore, the random walk hypothesis is rejected because of autocorrelation of weekly increments in the stock market index. Using the result that $\hat{\mathbf{M}}_{r}(q)$ is asymptotically equal to a weighted sum of autocorrelation coefficient estimates, the weights declining arithmetically,

$$
\hat{\mathbf{M}}_{\mathrm{r}}(q) \stackrel{a}{=} 2 \sum_{k=1}^{q-1}\left(1-\frac{k}{q}\right) \hat{\rho}(k)
$$

with $q=2$ we have

$$
\hat{\mathrm{M}}_{\mathrm{r}}(2) \equiv \widehat{\mathrm{VR}}(2)-1 \stackrel{a}{=} \hat{\rho}(1)
$$

For Botswana, $\widehat{\operatorname{VR}}(2)=1.39$ therefore the estimate of the first-order autocorrelation coefficient is 0.39 ; there is positive autocorrelation in the Botswana Share Market Index. A simple stochastic model which is consistent with this result is that returns follow an autoregressive process which results in short term fluctuations. Stationary, mean-reverting models are not appropriate for this market.

Similar results are obtained for Mauritius, the other small new market in the sample, and also the longer-established medium-sized markets of Egypt, Kenya, Morocco, Nigeria and Zimbabwe. For all of these markets, the homoscedastic and heteroscedastic random walk hypotheses are rejected because of positive autocorrelation in the series with estimated first-order autocorrelation coefficients in the range from 0.56 for Nigeria to 0.01 for Morocco.

The results for the large, but illiquid, South African market are different from those for all other markets in this study. For the logarithm of the JSE all-share index, the maximum absolute value of $Z(q)$ is 0.90 with $q=16$ and of $Z^{*}(q)$ is 0.96 for $q=2$. The random walk hypothesis is not rejected for this market. 
The key question that arises is, what explains the difference between the result for the JSE and those for the other seven African stock exchanges considered here? The obvious distinction between the JSE and the other exchanges is size, with the absolute value of both capitalization and turnover on the JSE approximately ten times that of the next largest market, Egypt. It may be, therefore, that there is some absolute size threshold that needs to be reached before a market can demonstrate a random walk. However, evidence from other parts of the world suggests that size alone is neither necessary nor sufficient to ensure that a market follows a random walk. There are small markets which follow a random walk, for example, Argentina (Urrutia, 1995), Indonesia, (Huang, 1995) and Turkey (Smith and Ryoo, 1998) and large markets which do not: Mexico (Urrutia, 1995) and Hong Kong and Korea (Huang, 1995).

A second factor that might be important in determining the characteristics of a stock market is liquidity. It is unlikely that a market with very low levels of turnover relative to its size would have a sufficiently active price formation process for the market to follow a random walk. One reason for this would be that with low levels of turnover, for many stocks there might be no trade from one period to the next, and hence no price changes. Evidence from other empirical studies suggests that liquidity is important. The Taiwan stock market, the most-liquid in the world but with similar capitalization in US\$ terms to the South African market, follows a random walk (Huang, 1995). Turkey, the most liquid European emerging market but relatively small, also follows a random walk (Smith and Ryoo, 1998). Argentina, the only market in Urrutia's (1995) study of Latin America found to follow a random walk was also the most liquid.

Earlier it was pointed out that the Johannesburg stock market is relatively illiquid by world standards with a turnover ratio of $18.3 \%$ in 1997 , and the second most liquid African market below Egypt which has a turnover ratio of $33.5 \%$. However, when considered in isolation, the liquidity data for South Africa are misleading because they only include trade on the Johannesburg market and some equities are cross-listed on other stock exchanges. In July 1997, $28 \%$ of JSE All-share capitalization was attributed to cross-listed companies. Trade in the shares of these companies which takes place on the more-liquid London and other markets is not captured by the JSE liquidity data. It is important to note that the Johannesburg share register is fully open and so shares can be transferred across markets without restriction. For example, someone can buy a Billiton share in Johannesburg and then apply for it to be moved to the London register of Billiton shares, and vice versa. Because of the open register arrangement, trades in London and elsewhere influence the price-formation process of cross-listed shares, and arbitrage will mean that any price differentials across registers will be small and temporary. Liquidity may therefore be important, even if not revealed by the liquidity figures for the JSE itself. The attraction of greater liquidity is powerful with four South African companies, Billiton, Anglo American Corporation, South African Breweries and Old Mutual moving their principal listings to London so that they can take advantage of the more-liquid international markets to raise funds for expansion. Given the many UK tracker funds, large companies listing in London generate an immediate demand for their stock.

Other factors would also seem important although many of them are difficult to quantify and so comparisons are somewhat impressionistic. The Johannesburg stock market is more 'institutionally mature' than other African markets - a term used by Huber (1997) who in work on the Vienna stock market found that as the market became institutionally more mature, stock prices more-closely approximated a random walk. What do we mean by 'more institutionally mature'? The financial sector in South Africa is relatively sophisticated and facilitates information flows in a manner that one would expect of a developed stock market. There is good quality research on JSE listed companies and many financial institutions have substantial in-house research facilities (Rathborne and Grosch, 1997). Futures contracts on equity indices have been traded since 1987, initially through Rand Merchant bank Ltd. The South African Futures Exchange (Safex) opened in August 1990 to trade derivatives; nonresidents have been permitted to participate since October 1991 and trading was fully automated in May 1996. The JSE closed its open outcry trading floor in June 1996 and moved to a screen-based trading system. A year later, the real time Stock Exchange News Service was introduced, facilitating rapid and wide dissemination of price-sensitive information. Furthermore, unlike Egypt, the JSE has no daily limits to fluctuations in stock prices. Such limits are known to result in departures from a random walk (Ryoo and Smith, 2001). Although the JSE has insider-trading laws, there has not been a single prosecution for insider trading since it became illegal in 1973. In 1997 the King Task Group reported into Insider Trading Legislation. The Group reported receiving arguments that insider trading makes stock markets more efficient by bringing information to the market more quickly. If information is withheld from the market, share prices are less likely to reflect the true value of stocks. Despite some problems with insider trading, JSE market governance would seem to be of high quality.

\section{CONCLUSIONS}

This paper used multiple variance ratio tests to examine the random walk hypothesis for eight African stock markets. In seven of these markets, Botswana, Egypt, Kenya, 
Mauritius, Morocco, Nigeria and Zimbabwe, the hypothesis is rejected because returns are autocorrelated. For South Africa, however, the JSE All-share index follows a random walk.

With so many new and relatively unresearched African stock markets, much work remains to be carried out. As more data become available it will be important to examine whether markets not presently tested follow a random walk. Also, where the random walk hypothesis is presently rejected, do those markets approach a random walk as they become more liquid and more institutionally mature? A study focusing on the prices of individual equities may be able to throw a different light on the size/liquidity question. When looking at individual stocks for a given market, market liquidity and institutional maturity are given. It should then be possible to address clearly the question: do large capitalization stocks follow a random walk?

\section{REFERENCES}

Campbell, J. Y., Lo, A. W. and MacKinlay, A. C. (1997) The Econometrics of Financial Markets, Princeton University Press, Princeton.

Cazenove (1997) Sub-Saharan Africa Stock Markets, Cazenove \& Co, London.

Chow, K. V. and Denning, K. (1993) A simple multiple variance ratio test, Journal of Econometrics, 58, 385-401.

Flemings Research (1997) Global Emerging Markets: Africa on Top, Robert Fleming, London.

Gonzalo, J. and Lee, T. H. (1996) Relative power of $t$ type tests for stationary and unit root processes, Journal of Time Series Analysis, 17, 37-47.

Hahn, G. J. and Hendrickson, R. W. (1971) A table of percentage points of the distribution of the largest absolute value of $k$ student $t$ variates and its applications, Biometrika, 58, 32332.

Hakkio, C. S. (1986) Does the exchange rate follow a random walk? A Monte Carlo study of four tests for a random walk, Journal of International Money and Finance, 5, 221-29.

Huang, B.-N. (1995) Do Asian stock market prices follow random walks? Evidence from the variance ratio test, Applied Financial Economics, 5, 251-56.

Huber, P. (1997) Stock market returns in thin markets: evidence from the Vienna stock exchange, Applied Financial Economics, 7, 493-98.

International Finance Corporation (1998) Emerging Markets Factbook, IFC, Washington DC.

Jefferis, K. (1995) The Development of stock markets in subSaharan Africa, South African Journal of Economics, 63, 346-63.

Johannesburg Stock Exchange (1997) Final Report by the King Task Group into Insider Trading Legislation, http://www.jse. co.za/

Kenny, C. and Moss, T. (1998) Stock markets in Africa: emerging lions or white elephants?, World Development, 26, 829-43.

Lo, A. and MacKinlay, A. C. (1988) Stock market prices do not follow random walks: evidence from a simple specification test, Review of Financial Studies, 1, 41-66.

Miller, R. G. (1981) Simultaneous Statistical Inference, 2nd edition, Springer-Verlag, New York.

Morgan Stanley (1993) Emerging Markets Investment ResearchAfrica, Morgan Stanley \& Co, New York.
Rathborne D. and Grosch, J. (Ed.) (1997) The LGT guide to World Equity Markets, Euromoney Publications, London.

Ryoo, H.-J. and Smith, G. (2002) Korean stock prices under price limits: variance ratio tests of random walks, forthcoming Applied Financial Economics, 12(8), 543-51.

Shiller, R. J. and Perron, P. (1985) Testing the random walk hypothesis: power versus frequency of observations, Economics Letters, 18, 381-86.

Smith, G. and Ryoo, H.-J. (1998) Variance ratio tests of the random walk hypothesis for European emerging stock markets, Department of Economics, School of Oriental \& African Studies.

Urrutia, J. L. (1995) Tests of random walk and market efficiency for Latin American emerging equity markets, Journal of Financial Research, 18, 299-309.

\section{APPENDIX: THE VARIANCE RATIO TEST}

The variance ratio is given by

$$
\operatorname{VR}(q)=\frac{\sigma^{2}(q)}{\sigma^{2}(1)}
$$

Lo and MacKinlay (1988) consider a sample of size $n q+1$ observations $\left(p_{0}, p_{1}, \ldots, p_{n q}\right)$. They show that unbiased estimates of $\sigma^{2}(1)$ and $\sigma^{2}(q)$ can be calculated as

$$
\hat{\sigma}^{2}(1)=(n q-1)^{-1} \sum_{k=1}^{n q}\left(p_{k}-p_{k-1}-\hat{\mu}\right)^{2}
$$

and

$$
\hat{\sigma}^{2}(q)=h^{-1} \sum_{k=q}^{n q}\left(p_{k}-p_{k-q}-q \hat{\mu}\right)^{2}
$$

where $\hat{\mu}$ is the sample mean of $\left(p_{t}-p_{t-1}\right)$ and

$$
h \equiv q(n q+1-q)\left(1-\frac{q}{n q}\right)
$$

Since

$$
\widehat{\mathrm{VR}}(q)=\frac{\hat{\sigma}^{2}(q)}{\hat{\sigma}^{2}(1)}
$$

define

$$
\hat{\mathbf{M}}_{\mathrm{r}}(q) \equiv \widehat{\mathrm{VR}}(q)-1
$$

Under homoscedasticity, their standard normal test statistic, $Z(q)$, is

$$
Z(q)=\frac{\sqrt{n q} \hat{\mathbf{M}}_{\mathrm{r}}(q)}{\hat{\sigma}_{0}(q)}
$$

where

$$
\hat{\sigma}_{0}(q)=\left(\frac{2(2 q-1)(q-1)}{(3 q)}\right)^{1 / 2}
$$

Using the result that $\hat{\mathbf{M}}_{\mathrm{r}}(q)$ is asymptotically equal to a weighted sum of autocorrelation coefficient estimates, 


$$
\hat{\mathbf{M}}_{\mathrm{r}}(q) \stackrel{a}{=} 2 \sum_{k=1}^{q-1}\left(1-\frac{k}{q}\right) \hat{\rho}(k)
$$

their test statistic for a heteroscedastic increments random walk, $Z^{*}(q)$, is

$$
Z^{*}(q)=\frac{\sqrt{n q} \hat{\mathbf{M}}_{\mathrm{r}}(q)}{\hat{\sigma}_{e}(q)}
$$

and

$$
\hat{\delta}_{k}=\frac{n q \sum_{j=k+1}^{n q}\left(p_{j}-p_{j-1}-\hat{\mu}\right)^{2}\left(p_{j-k}-p_{j-k-1}-\hat{\mu}\right)^{2}}{\left[\sum_{j=1}^{n q}\left(p_{j}-p_{j-1}-\hat{\mu}\right)^{2}\right]^{2}}
$$

where

$$
\hat{\sigma}_{e}(q)=\left(4 \sum_{k=1}^{q-1}\left(1-\frac{k}{q}\right)^{2} \hat{\delta}_{k}\right)^{1 / 2}
$$


Copyright of Applied Financial Economics is the property of Routledge, Ltd. and its content may not be copied or emailed to multiple sites or posted to a listserv without the copyright holder's express written permission. However, users may print, download, or email articles for individual use. 